\title{
La participación del clero secular en las congregaciones de los pueblos de indios: el caso de Atlacomulco y San Juan de los Jarros 1592-1604*
}

\author{
por
}

\author{
Felipe Santiago Cortez ${ }^{1}$ \\ El Colegio de Michoacán
}

\begin{abstract}
El objetivo de este artículo es analizar la participación del clero secular en las congregaciones de los pueblos de indios. Mi contribución al debate sobre las congregaciones es estudiar el papel de los curas como actores sociales complejos que no se circunscribe a escenarios propios de su actividad religiosa, sino que actúan como verdaderos negociadores, intermediarios y agentes políticos de los pueblos. Para ello, analizo el caso de Juan González de Urbina, cura de Atlacomulco, personaje principal del documento inédito de la congregación de Atlacomulco.
\end{abstract}

Palabras Claves: Curas; congregación; pueblos; beneficios eclesiásticos.

Cómo Citar Este Artículo / Citation: Santiago Cortez, Felipe, "La participación del clero secular en las congregaciones de los pueblos de indios: el caso de Atlacomulco y San Juan de los Jarros 1592-1604", Revista de Indias, LXXXI/283 (Madrid, 2021): 669-701. https://doi.org/10.3989/revindias.2021.019.

* Este artículo nació a raíz de mi tesis doctoral dirigida por mi querida maestra Margarita Menegus. Agradezco las sugerencias de los dictaminadores que enriquecieron el contenido de este escrito. Asimismo, extiendo mi agradecimiento al Consejo Nacional de Ciencia y Tecnología (México) por la estancia posdoctoral realizada en El Colegio de Michoacán, así como a los doctores Luis Alberto Arrioja y Thomas Calvo, adscritos a tan honorable institución, por leer y comentar este artículo. Por último, agradezco a la maestra Gabriela Nieblas Gutiérrez (mi esposa) sus comentarios y correcciones.

${ }^{1}$ scfelipe@gmail.com, ORCID iD: https://orcid.org/0000-0003-0017-4409 
En la historia sobre los pueblos de indios hay varios procesos que han sido abordados por distintos especialistas, entre ellos se encuentra la política de congregación, cuyo principal objetivo era remover a los indios de sus lugares originarios a centros urbanos de más fácil acceso. En este artículo me centraré en el segundo periodo de dicha política que va de 1590 a 1604, su repercusión fue determinante en varios pueblos de indios, sobre todo, en el ámbito político y territorial. Algunos estudios pusieron su atención en el impacto que tuvo al interior de los pueblos ya que modificó de manera sustancial los padrones de asentamientos. Otros investigadores observaron que las reducciones funcionaron para controlar los recursos de los pueblos y así también dejar claro cuáles eran las tierras baldías que podían ser mercedadas a españoles ${ }^{2}$. Dicho lo anterior, mi propuesta en este artículo es acercarse al proceso de reducción de los pueblos desde una óptica social poco tratada, específicamente, me centraré en el papel del clero secular.

En ese sentido, el objetivo es revalorar la labor de los curas seculares durante las congregaciones, considerándolos como actores sociales complejos cuyo papel no solamente se circunscribe a escenarios propios de su actividad religiosa, sino que actúan como verdaderos negociadores, intermediadores y agentes políticos de los pueblos. Para ello, analizo el caso del cura Juan González de Urbina quien obtuvo su beneficio eclesiástico en el pueblo de Atlacomulco y se convirtió en un líder local promotor de la congregación de 1604, al aliarse con los linajes principales y al oponerse a otros actores sociales establecidos antes de su llegada como fueron la familia de encomenderos y los caciques mazahuas.

Aun cuando se estudia el caso de un cura que repercutió en su ámbito local, considero que este trabajo coadyuva a explicar desde otra óptica el proceso congregacional desde un enfoque social, donde la participación del clero secular y otros actores como los principales, los caciques y el encomendero tuvieron implicaciones determinantes en la historia de los pueblos de indios.

Los especialistas han vislumbrado diferentes papeles de los religiosos, ejemplo de ello, Bernardo García en su investigación sobre los pueblos de la sierra de Puebla, anuncia la importancia de los eclesiásticos ${ }^{3}$; Rodolfo Aguirre

${ }^{2}$ La merced es un favor concedido en nombre de su majestad, otorgado a aquellos que habían servido a la corona, por su participación militar. Véase Chevalier, 1976: 174.

${ }^{3}$ Frailes y curas convivieron en los pueblos. Los curas supusieron un mayor número que los frailes. Su contacto cotidiano con los indios propició su influjo en la estructura social, puesto que eran depositarios y ejecutores del dominio político y económico de la Iglesia. Por ello se convirtieron en verdaderas figuras políticas que participaban en asuntos de elecciones dentro de los pueblos de indios. Véase García Martínez, 1987: 96. 
tiene varios textos donde señala el papel del clero regular en los pueblos de indios, entre sus postulados principales está la relación de poder frente a los caciques y encomenderos ${ }^{4}$; William Taylor ve claramente el liderazgo de los curas en distintos pueblos de indios del centro y occidente de la Nueva España para las primeras décadas del siglo XVII y XVIII ${ }^{5}$. El derrotero de este trabajo es analizar con profundidad la participación del cura Juan González de Urbina en el proceso congregacional de San Juan de los Jarros inserto en un siglo y periodo poco estudiado, a saber, 1592-1604, a partir de la revisión de documentos, entre ellos, el documento de congregación del pueblo sujeto de San Juan de los Jarros 6 , además de varios ramos del Archivo General de la Nación y del Archivo General de Indias.

\section{LAS CONGREGACIONES EN LOS PUEBLOS DE INDIOS}

Uno de los primeros estudios sobre la reducción de los pueblos fue el artículo de Howard F. Cline en 1949, donde se expuso que la mayoría de los pueblos de la Nueva España tenían una constante en su patrón de asentamiento. Los caseríos indígenas estaban dispersos, lo que dificultaba la administración tanto civil como religiosa ${ }^{7}$. Durante la administración del Conde de Monterrey se mandaron 30 comisiones en septiembre de 1598 para reconocer el terreno y, sobre todo, tener cuidado con los problemas que pudieran presentarse en los reajustes territoriales ${ }^{8}$. El autor considera que las congregaciones realizadas entre 1595 y 1605 , en su mayoría, fueron verdaderos cambios en lo territorial en virtud de que desaparecieron cientos de establecimientos menores ${ }^{9}$. En este primer acercamiento sobre las congregaciones, Cline no

${ }^{4}$ Aguirre Salvador, 2014: 10-44.

5 Taylor, 1999: 128-135, 185.

${ }^{6}$ La congregación del pueblo sujeto a San Juan de los Jarros aparece en un documento inserto en un expediente de 1712, del Archivo Municipal de Ixtlahuaca, Ixtlahuaca, Estado de México (en adelante AMI), donde los pueblos sujetos de San Bartolomé, Santo Domingo y San Felipe, todos de la jurisdicción de San Juan, se quejan contra Gaspar de Oña y su esposa Leonor de los Ángeles, españoles que trataron de asentarse en las tierras de estos lugares. Los historiadores Jesús Guadarrama y Sergio López se encargaron de resguardar tan importante memorial con la signatura: Sección Histórica (SH), documento uno. Por tanto, en adelante citaremos este documento así: AMI-SH, doc. 1. He de señalar que este valioso memorial fue publicado en el año 2020 por la Universidad Nacional Autónoma de México, con un prólogo realizado por Margarita Menegus y un estudio introductorio y la paleografía del documento de mi autoría.

7 Cline, 1949: 349-350.

8 Ibidem: $352-353$.

9 Ibidem: 369. 
ahondó en el tema, solo analizó las implicaciones generales del proceso a la vista de las ordenanzas emanadas desde la Corona y puestas en práctica por el virrey Conde de Monterrey, sin embargo, sentó las bases para analizar los alcances espaciales de las congregaciones.

Entre los especialistas más importantes en los estudios sobre las congregaciones de los pueblos de indios, sin duda alguna, está Ernesto de la Torre Villar. En 1952 hizo un análisis sobre el artículo que publicó Lesley Byrd Simpson (1934), en el cual hace referencia a la relación de la visita y demarcación del pueblo de Tianguistenco, en el actual estado de Hidalgo ${ }^{10}$. Más que fijarse en las implicaciones espaciales propias de la congregación, de la Torre puso su interés en las repercusiones y manifestaciones adversas que los indios interpusieron a las autoridades novohispanas. Para 1597, la configuración interna de Tianguistenco era de 177 tributarios que labraban una sementera de maíz, además de poseer ricos recursos naturales como afluentes de aguas y tierras fértiles.

Los pueblos sujetos esgrimieron su preocupación por dejar sus cultivos: «dicen que en su pueblo hacen sus sementeras y que por estar alrededor del monte las están guardando, y mudándose a la cabecera es fuerza irlas a hacer en sus tierras, porque no las hay en la dicha cabecera $\rangle^{11}$. La postura de estos indios tributarios no fue respaldada por la encomendera doña María de Mosquera, así que el juez congregador hizo un oficio para el rey argumentando los beneficios de la congregación para los pueblos sujetos de Tianguistenco en 1604, además de señalar lo fácil que sería la administración de los indios. Resultado de este ejercicio, Ernesto de la Torre abrió el debate sobre la funcionalidad de las congregaciones en los pueblos o sus repercusiones negativas dado que, en muchas ocasiones, los indios perdieron territorios; estos argumentos fueron retomados por estudiosos en décadas posteriores.

Otro texto básico sobre las reducciones es el artículo de Peter Gerhard publicado en $1977^{12}$. Entre los aportes más importantes de su investigación fue aclarar los efectos positivos y negativos de las congregaciones en los pueblos. Para él no se puede negar la adquisición de tierras por parte de los españoles, ya que, al abandonar los indios sus lugares, se consideraron tierra realenga y, por lo tanto, digna de repartirse a españoles mediante una merced, sin embargo, en algunas partes de la Nueva España, se consolidó el gobierno indígena, además de crear verdaderos pueblos ordenados con tierras para sembrar ${ }^{13}$.

\footnotetext{
10 Torre Villar, 1952.

11 Ibidem: 193-194.

12 Gerhard, 1977.

13 Ibidem: 385.
} 
Una década más tarde, Bernardo García Martínez presentó su obra sobre los pueblos de la sierra poblana ${ }^{14}$. En su investigación planteó que, debido a las concepciones renacentistas europeas del espacio, los españoles preferían la tendencia a privilegiar las estructuras definidas y concentradas, de tal manera que por la naturaleza del gobierno y de la administración de los servicios religiosos, así como la administración civil y eclesiástica, demandaron de los pueblos límites y centros que regularan las actividades ${ }^{15}$. Para Bernardo García, las congregaciones fueron un logro duradero ya que respondieron a un programa definido y bien organizado donde se designaron agrimensores auxiliados por agentes cercanos a los pueblos como los gobernadores y los alcaldes mayores. Al igual que Gibson, el autor señaló que las congregaciones por sí mismas no alteraron la integridad de los pueblos, además de que los propios naturales participaron activamente en su realización.

Al paso de los años y con vasta experiencia, en 1995, Ernesto de la Torre Villar escribió nuevamente sobre las congregaciones de los pueblos de indios. De sus postulados iniciales sobre lo perjudicial de dicha política no se desdijo, al contrario, continuó con su visión crítica. Para él, las reducciones conllevaron una labor imperiosa y perjudicial debido a la alteración que implicó para los pueblos, de hecho, prácticamente los destruyó: «de muchas formas de relación social y política existentes en la época prehispánica, diluyó nexos de parentesco, de relaciones étnicas... con las reducciones, el dominio de los conquistadores se hizo más patente $\rangle^{16}$. En otras palabras, este autor consideró la congregación como una injerencia directa en la estructura política prehispánica que culminó con su destrucción.

En años recientes los trabajos sobre las congregaciones se han diversificado, hay propuestas metodológicas interesantes para abordarlas. Un ejemplo de ello es la invitación de Juan Manuel Pérez Zevallos para analizar dicha política ${ }^{17}$. En su tesis toma como punto clave los movimientos de población que se circunscriben en una gama de posibilidades de análisis, de hecho, el propio concepto alude al dinamismo y transformación que repercuten en el orden preestablecido, sin duda alguna, la política de congregación cumplió con ese reordenamiento y por sus características se pueden derivar varias aristas de análisis ${ }^{18}$. Entre ellas, Pérez Zevallos considera que las causas y motivaciones para los procesos congregacionales determinarán las reacciones internas en cada

\footnotetext{
${ }^{14}$ García Martínez, 1987: 96.

15 Ibidem: 151-152.

16 Torre Villar Ernesto, 1995: 64.

17 Pérez Zevallos, 1994.

18 Ibidem: 170.
} 
caso. El segundo nivel de análisis es entender las distintas expresiones y formas de esos movimientos, de tal suerte que se pretende vislumbrar si esos reajustes fueron voluntarios o impuestos ${ }^{19}$. Por la naturaleza espacial de mi lugar de estudio, el norte del valle de Toluca, la variable que más me interesa es la que el autor llama «morfología de los movimientos» ${ }^{20}$ que consiste en analizar los movimientos inter-culturales, es decir, qué ocurre cuando se congregan distintas etnias en un mismo espacio, si bien es cierto, no es el objetivo de este escrito, hay que advertir que en nuestro ámbito de injerencia hay otomíes, nahuas y mazahuas. Indudablemente, esta forma de análisis puede ser un modelo para abordar las congregaciones con mayor profundidad.

Francisco Jiménez Abollado hace otro planteamiento sugerente para abordar las congregaciones. Él sostiene que mediante los estudios etnográficos se pueden entender los comportamientos de distintos actores sociales ${ }^{21}$ y bajo esta óptica estudió la congregación de San Francisco Temango de 1598 localizado en el valle del mezquital. La descripción espacial es fuente vital para comprender por qué congregar a los pueblos, Temango está ubicado en una zona geocultural de la Sierra Alta, al norte del actual estado de Hidalgo ${ }^{22}$, por el aspecto físico hay una diversidad de grupos que se asentaron en las faldas de las montañas, de hecho, esto fue pieza fundamental para la organización de la congregación. El autor también advierte el protagonismo de las autoridades españolas «agentes aculturadores» amén de los sujetos pasivos, los indígenas ${ }^{23}$. La información que se confeccione durante el proceso de congregación emana de los funcionarios enviados por el virrey, sin desestimar los testimonios de personas como los padres doctrineros y las autoridades locales, quienes forman parte vital para entender las problemáticas, no obstante, considero que los documentos de congregación pueden dar mayores aportes a la discusión historiográfica en cuanto al acercamiento hacia los problemas y sus complejidades.

Para cerrar este balance, hay un trabajo que habla sobre el papel de la iglesia novohispana en la segunda etapa de las congregaciones a raíz del tercer concilio provincial efectuado en 1585. Rodolfo Aguirre hace un recuento contextual sobre la iglesia misional y su importancia en el proceso de reducción de los pueblos en la segunda mitad del siglo $\mathrm{XVI}^{24}$ en donde la participación del clero secular fue incipiente y con muy pocas implicaciones. No obstante, con los cambios dados

\footnotetext{
19 Ibidem: 172.

20 Ibidem: 176.

21 Jiménez Abollado, 2009.

22 Ibidem: 46.

23 Ibidem: 47.

24 Aguirre Salvador, 2013.
} 
por el primer concilio provincial en 1555 aunados a la visita en 1568 de Juan de Ovando donde los curas detallaron las condiciones de las doctrinas, se dieron cuenta de las deficiencias del clero misional y con en ello las críticas y luchas en pugna por la doctrina de los pueblos de indios ${ }^{25}$. Las propuestas en los memoriales del tercer concilio coincidían en la necesidad de congregar a los indios alrededor de las iglesias ya que priorizaba las necesidades espirituales, además el papel del clero secular era básico, de tal suerte que el propio consultor del concilio, el doctor Hernando Ortiz, enumeró las ventajas que tenían los curas en la conversión de las almas ${ }^{26}$, en párrafos precedentes este personaje fue vital para la asignación del beneficio eclesiástico de nuestro cura Juan González de Urbina. También cabe destacar que una de las conclusiones mencionadas por Rodolfo Aguirre es que, a diferencia de las órdenes mendicantes que pugnaban por la protección de las tierras de los pueblos, el clero secular no reparaba en ello, al contrario, veía necesario el traspaso de las tierras desocupadas a los colonos españoles ${ }^{27}$. Tal vez falta matizar esa idea con más trabajos que detallen este proceso, para nuestro caso, al cura Juan González pugnará y, en algunos casos, defenderá las tierras inmemoriales de los linajes tradicionales de San Juan de los Jarros.

En los últimos 70 años se han escrito diferentes trabajos sobre las congregaciones en sus dos diferentes etapas ${ }^{28}$, es probable que dentro de la historiografía colonial no

25 Ibidem: 140.

26 Ibidem: 145-146.

27 Ibidem: 146.

${ }^{28}$ Hay varios estudiosos que han abordado las congregaciones, analizar cada texto rebasaría los límites de este artículo, sin embargo, señalaré algunos. Para la zona Puebla Tlaxcala, en especial los señoríos de Tecamachalco y Quecholac, Hildeberto Martínez encontró que la aplicación de la política de congregación significó una táctica perfecta para desposeer a los señores naturales tanto de las tierras como de sus maceguales terrazgueros, por lo tanto, la congregación ofrecía la oportunidad para que los colonizadores reclamaran las tierras desocupadas (véase Martínez, 1994: 98). En el valle de Toluca, Noemí Quezada contribuyó con un análisis general de las repercusiones territoriales de algunos pueblos, además de ofrecer una periodicidad que va desde las congregaciones voluntarias en 1590 hasta las forzosas entre 1595 y 1602 (véase Quezada, 1990: 81). El trabajo de Daniele Dehouve sobre el estado de Guerrero, en particular del pueblo de indios de Tlapa, nos da cierta luz sobre el nivel de permisibilidad por parte de los indios para su realización, de tal suerte, que la participación de los agustinos en su primera congregación entre 1550 y 1570 fue vital. Sin embargo, las congregaciones de finales del siglo XVI fracasaron por la nula cooperación de la orden agustina, ya que esta representaba la apertura del clero secular a sus jurisdicciones. (Confróntese con Daniele Dehouve, 2001: 132-136). Para la zona maya, la investigación de Nancy Farris es básica para entender las reducciones de los pueblos, por ejemplo, ella encontró un proyecto bien estructurado por parte de la orden franciscana donde efectivamente, en su primera congregación de 1544, pudieron administrar mejor a los pueblos (Farris, 1992: 158-160). Una investigación reciente pone su atención en aspectos en los que los especialistas poco habían reparado. El trabajo de Luis Arrioja sobre las congregaciones de la alcaldía mayor de Nexapa en Oaxaca, evidencia que los 
se ha hecho justicia sobre sus implicaciones en los pueblos de indios, quizá por la escasa documentación o el interés personal de cada especialista, sin embargo, es un aliciente el que los últimos trabajos problematicen este proceso, y de ello va la propuesta aquí presentada. He notado la ausencia de los elementos sociales que incidieron en los procesos congregacionales; si bien es cierto que se da por entendido la participación de diversos actores sociales como el caso del clero secular y regular, los jueces de congregación, además de los indios, creo que aún falta puntualizar qué papel desempeñó el clero secular en las congregaciones de los pueblos. En un intento por responder esta pregunta, como ya mencioné, analizaré el caso del cura Juan González Urbina. Para ello, he dividido las siguientes líneas en tres parágrafos: el primero, abordará el contexto de secularización del valle de Toluca; en el segundo, analizaré, grosso modo, el entorno previo a la llegada de Juan González de Urbina a Atlacomulco; y, por último, su participación en el proceso de congregación.

\section{Los PRIMEROS CURAS EN EL VALLE DE TOLUCA}

La llegada del clero secular al valle de Toluca responde a una etapa crucial en la iglesia novohispana, sobre todo, con el ascenso de Alonso de Montufar y las reformas tridentinas tendientes a fortalecer al clero eclesial, y de cierta manera desestimar el trabajo de los frailes en el valle. A raíz de la Junta Magna de 1568 se puntualizaron los problemas de las Indias, entre ellos, los asuntos eclesiásticos y de evangelización, de tal manera que con Juan de Ovando comenzó el análisis sobre el estado que guardaban las jurisdicciones, razón de ser de las descripciones que a petición del arzobispo solicitaron a los curas diocesanos y que éstos enviaron en $1569^{29}$. Para el valle de Toluca hay informes los primeros beneficios encontrados en los pueblos de indios serranos. En Xalatlaco estaba el cura Juan de Sigura ${ }^{30}$, en la parroquia de San Pedro Atlapulco se asignó al bachiller Pedro de Salamanca que tenía por visitas a los pueblos de Capulhuac, Ocoyoacac, Tepexoyuca y Cuapanoaya ${ }^{31}$;

\footnotetext{
recursos naturales, como las afluentes del río Tehuantepec, de cierta manera, determinaron las congregaciones. De hecho, la novedad y la propuesta se vuelven sugerentes pues un recurso hídrico alcanzó un gran peso al suministrar los recursos de subsistencia y definió el tipo de cultivos, de modo que más allá de que los recursos naturales fueran un medio físico, se convierten en un factor que explica las reducciones (véase Arrioja Díaz Virruell, 2008: 75-90).

29 Aguirre Salvador, 2013: 140.

30 Descripción del Arzobispado de México..., 1897: 113.

31 Ibidem: 227.
} 
en Xiquipilco (de configuración étnica otomí) fue asignado Francisco de Agui$\operatorname{lar}^{32}$. Para la zona norte (Ixtlahuaca) estaba el cura Juan Venegas ${ }^{33}$.

\section{Mapa 1. Primeros curas asignados al valle de Toluca en 1569}

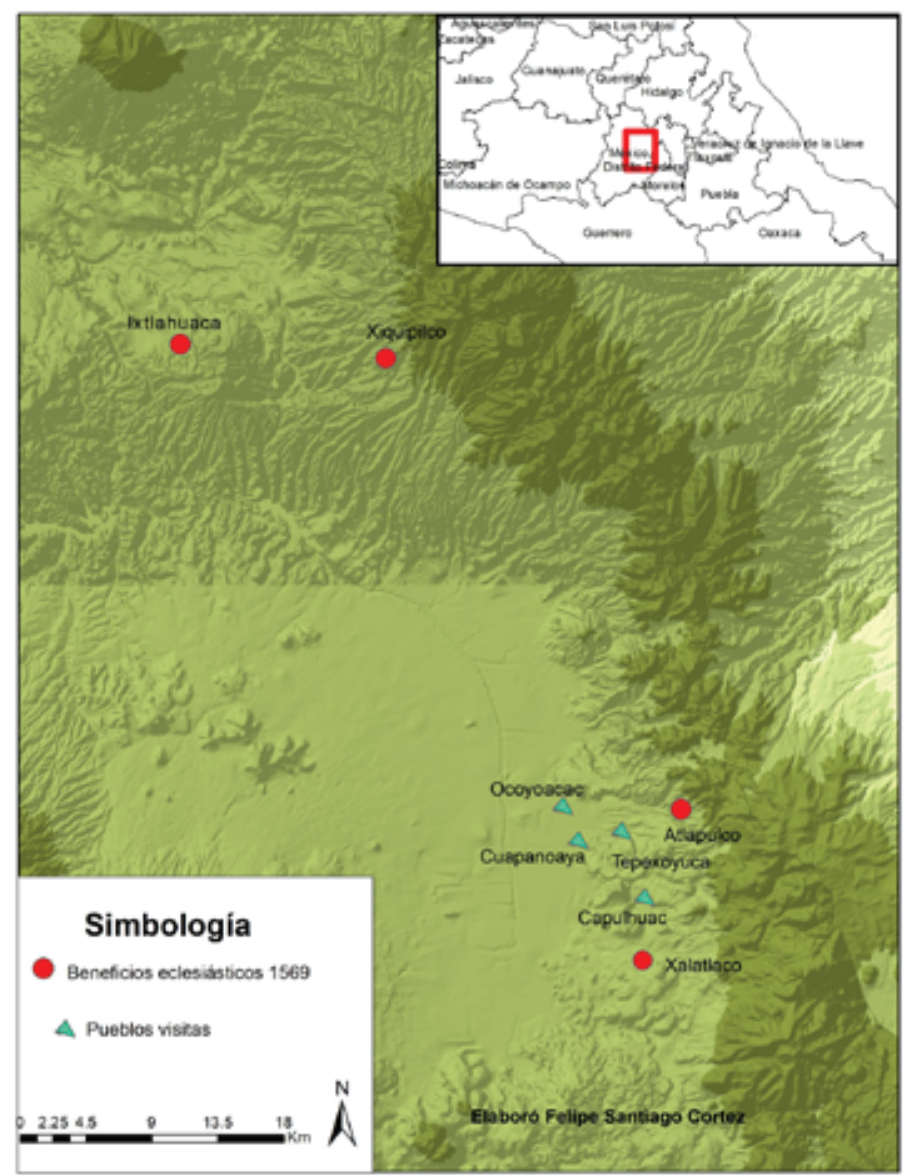

Fuente: Reconstrucción hipotética, a partir de la Descripción del Arzobispado de México..., 1897: 113.

El orden social con respecto a los primeros años de conquista había cambiado, el poder del rey y su control en la Nueva España se hacía cada vez más

\footnotetext{
32 Ibidem: 235.

33 Ibidem: 101.
} 
puntual, su apoyo al naciente clero secular y a la Universidad dio un impulso a la inserción de curas en los pueblos y con el apoyo de los encomenderos, prosperaron y fueron avanzando en influencias y poder. Pero había un riesgo en instaurar curatos; como bien se sabe los miembros de alguna orden mendicante hacían ciertos votos monásticos cuyo objetivo era conllevar una vida espiritual a la salvación a través de la renuncia de placeres terrenales, uno de los votos era el de pobreza que los ligaba a una vida sin ataduras o inclinación afectiva a lo material (no tener nada, no poseer nada). Votos que el clero secular no hacía, y en muchas de las ocasiones los curas amasaban territorios y fortunas.

Idealmente se les pedía a los clérigos seculares llevar consigo a su profesión algún bien o pensión que les proporcionara un nivel de vida decente, según los cánones de Trento, no debía impartirse la ordenación a menos de que el candidato demostrara contar con tal fuente de ingresos ${ }^{34}$. La Corona pagaba a los frailes y a los sacerdotes seculares que administraban a los pueblos de indios ${ }^{35}$, los curas en los pueblos mineros no indígenas debían ser pagados con el producto del diezmo de los pobladores. En referencia a la construcción de las iglesias catedrales, a mediados del siglo XVII, la responsabilidad financiera era repartida por la Real Hacienda, el encomendero y los indios, todos ellos se dividían un tercio de los gastos totales ${ }^{36}$.

Ahora bien, acontecimientos tales como el apoyo real y del propio arzobispo en el fortalecimiento del clero secular, además de los cambios suscitados en el tercer concilio provincial tendientes a señalar la pronta claridad en la administración religiosa en los pueblos de indios, permitieron la asignación de los primeros curas al valle, además de aprovechar a los primeros bachilleres graduados de la Universidad y así implementar los planes del clero.

El contexto antes de la llegada del cura Juan González de Urbina a Atlacomulco

El encomendero de Atlacomulco fue Francisco de Villegas en $1537^{37}$, y permaneció como tal 15 años. A su muerte, le sucedió su hijo Manuel Villegas y, por último, Pedro Villegas. La familia Villegas tuvo en encomienda a los indios de Atlacomulco cerca de 58 años.

\footnotetext{
34 Taylor, 1999: 184.

${ }^{35}$ Recopilación de las leyes..., 1681, libro I, título XIII, ley X.

${ }^{36}$ Solórzano y Pereira, 1930: 5

37 Gerhard, 2000: 355, 364.
} 
Cuadro 1. La familia Villegas en Atlacomulco de 1537-1595

\begin{tabular}{|l|l|l|}
\hline \multicolumn{1}{|c|}{ AÑO } & \multicolumn{1}{|c|}{$\begin{array}{c}\text { NOMBRE } \\
\text { DEL ENCOMENDERO }\end{array}$} & \multicolumn{1}{c|}{ FUENTE } \\
\hline $1537-1552$ & Francisco de Villegas & Gerhard, 2000: 355, 364. \\
\hline \multirow{2}{*}{$1552-1570$} & Manuel Villegas & AGN, Tierras, vol. 1834, exp. 4, f. 79. \\
\cline { 3 - 3 } & AGN, Mercedes, vol. 9, f. 270. \\
\hline $1570-1595$ & Pedro Villegas & AGN, Mercedes, vol. 17, exp. 289, f. 74v. \\
\hline
\end{tabular}

La transformación de los señoríos prehispánicos inició con la identificación por parte de los españoles entre los lugares que a su juicio podían considerarse como sitios de residencia de los tlahtoque y aquellas poblaciones que tenían una posición subordinada ${ }^{38}$. La designación para determinar los lugares de jerarquía se derivó de un estudio atento de la realidad nativa y tal vez utilizaron ciertos documentos donde detallaban registros censales, catastrales y tributarios. Probablemente uno de los testimonios consultados fue la Matrícula de Tributos en donde se registraron los lugares destinados al acopio del tributo.

En esa identificación de los lugares, hay un asunto que no concuerda con la evidencia. Gracias al documento de congregación sabemos que el lugar donde estuvieron los linajes prehispánicos fue San Juan de los Jarros, también conocido como Cuiyatepec $^{39}$. Sin embargo, su historia es omitida en los documentos y es aquí donde surgen varias interrogantes, por ejemplo, ¿qué ocurrió después de la conquista? y ¿por qué el encomendero Francisco de Villegas nunca mencionó la existencia de San Juan y sí la de Atlacomulco? Para entender este problema tan complejo es necesario armar las piezas del mosaico. En El Libro de las tasaciones de pueblos de la Nueva España, se registraron dos lugares: «Temagascalzingo, que es la una estancia... [hay otra estancia] que se dice Acuzilapa ${ }^{40}$, esto en 1537; y en La Suma de Visitas de 1548 se menciona que: «Atlacomulco es cabecera, y tenía tres estancias sujetas; Techichilco, Tepeolulco y Tlamacozcacingo» ${ }^{41}$.

Ahora bien, nótese que en ambas fuentes todavía no habían asignado patronímicos. De las estancias referidas todavía algunas se pueden localizar. En la

38 González Reyes, 2013: 122.

39 Derivado del náhuatl que significa «El cerro de las ranas» (Cuitlatl= rana, tepetl = cerro y co, locativo). Véase Molina, 1944: 157.

${ }^{40}$ El Libro de las tasaciones..., 1952: 74.

${ }^{41}$ Paso y Troncoso, 1905: 23. 
documentación colonial del siglo XVII hay referencias de Acucilapa, de hecho, es uno de los pueblos sujetos más importantes de población mazahua hasta el día de hoy. Temascalcingo tiene como santo patrono a San Miguel; de Tepeolulco su advocación fue San Francisco, de población netamente mazahua ${ }^{42}$. Con respecto a Techichilco no existe ningún registro. Según La Suma de Visitas los pueblos que colindaban con Atlacomulco eran: «parte al norte con Xilotepec y Acámbaro y al sur con Xocotitlán y Maravatio y al levante con Xicotitlán». ${ }^{43}$

\section{Mapa 2. Límites de Atlacomulco en 1548}

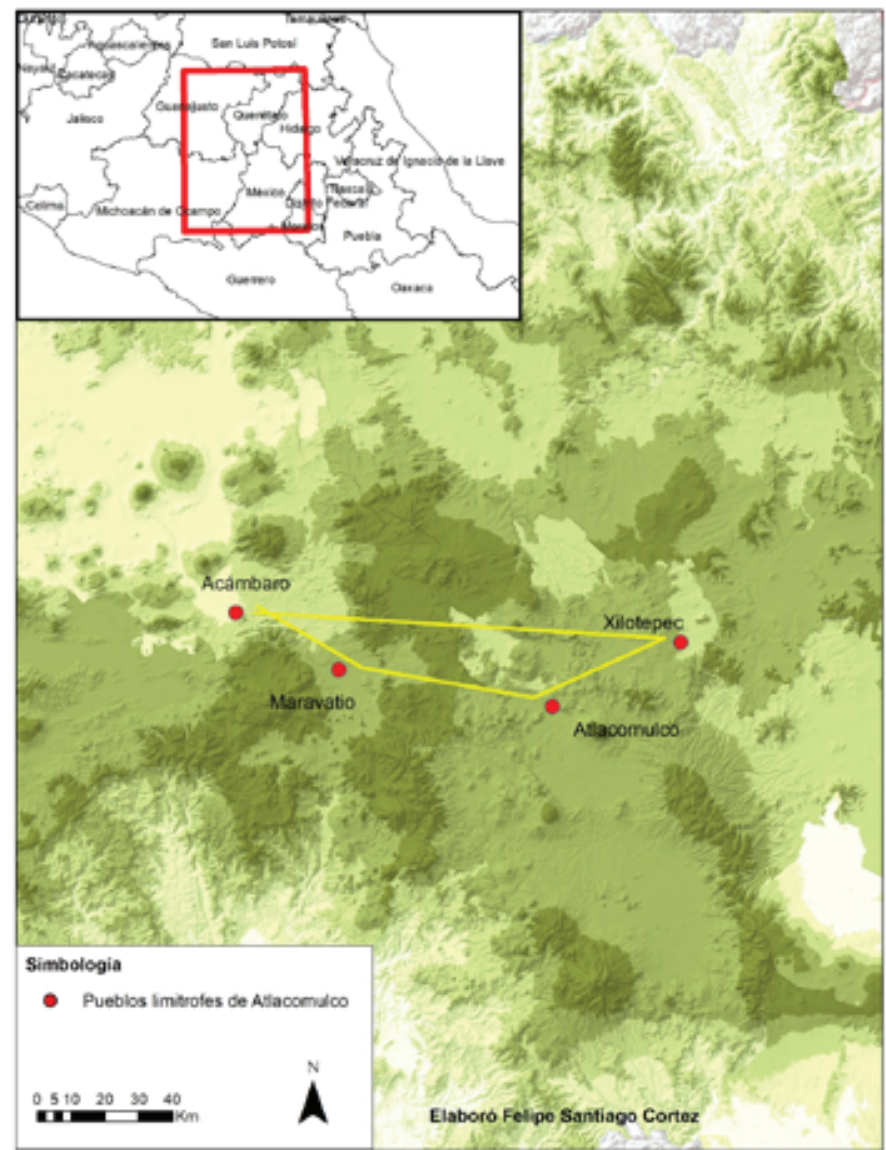

Fuente: Reconstrucción hipotética a partir del texto de Paso y Troncoso, 1905: 23.

\footnotetext{
${ }^{42}$ AMI-SH, doc. 1, f. 9.

${ }^{43}$ Paso y Troncoso, 1905: 23.
} 
Hay un aspecto digno de destacar, el pueblo Atlacomulco no está en ningún códice o crónica temprana, su primera referencia se encuentra en El libro de las tasaciones. Atando cabos, hay un cacique homónimo del encomendero procedente de Temascalcingo, indio que estuvo reeligiéndose por más de 12 años en los cabildos; además de aprovecharse del máximo puesto, en su administración compró varias estancias ganaderas y caballerías de tierras, convirtiéndose en un rico y próspero terrateniente de todo el norte del valle de Toluca.

Ahora bien, es probable que se tejió una alianza entre el encomendero y sus hijos con dicho cacique procedente de Temascalcingo para desplazar a los linajes gobernantes de San Juan de lo Jarros y relegarlos del poder político. Se necesitaba una nobleza indígena, capaz de negociar y, sobre todo, recabar los tributos y servicios, interés primordial del encomendero. En esta etapa de reconocimientos y primeras alianzas se dio la primera congregación de 1550, sin embargo, es una realidad que hay pocos testimonios donde se haga mención de su aplicación en el valle de Toluca ${ }^{44}$, para nuestro caso no existe algún memorial que enuncie una reorganización espacial pero, por las referencias antes descritas, es de suponer la participación del encomendero en su ejecución con miras a aprovechar todos los recursos político-tributarios de su encomienda y así aliarse con los caciques mazahuas, además de separar tanto espacial y como políticamente a los linajes de San Juan de lo Jarros. Por tal razón antes de la llegada del cura Juan González de Urbina el orden establecido dictaba una alianza funcional bajo los intereses de dos actores sociales como fue el encomendero y su homónimo cacique.

\section{El cura: sus desavenencias con el encomendero y el Cacique Mazahua}

El cura llegó a Atlacomulco en $1575^{45}$. En una relación de méritos ${ }^{46}$ que realizó en 1576 ante el rey, se puede conocer su procedencia y las relaciones e influencias que tenía en el orden político y religioso. Su padre era Andrés González avecindado en la Ciudad de México quien se casó con Juana Ramírez «y que durante su matrimonio vieron (sic) por su hijo legítimo al dicho Juan González de Urbina que es uno de los honrados clérigos que hay en esta

44 René García contabilizó 12 pueblos de indios que tuvieron registro de la congregación de 1550, del norte del valle de Toluca tan solo hay referencias de Ixtlahuaca. García Castro, 1999: 160 .

45 «En ese mismo tiempo proveyó a los naturales los servicios y obtuvo su beneficio por oposición en el pueblo de Atlacomulco en este octubre pasado», Archivo General de Indias, Sevilla (AGI), 215, núm. 13, f. 2v.

${ }^{46}$ Las «relaciones de méritos» constituían el medio material que permitía al pretendiente obtener el cargo o prebenda solicitados. (Véase Espejo, 1926: 1). 
Nueva España $»^{47}$. Desde muy joven sirvió como capellán en la catedral de la Ciudad de México, según el testimonio del tesorero de la catedral el canónigo Pedro Garcés quien lo conoció por más de 10 años ${ }^{48}$.

Todo parece indicar que el presbítero estaba bien relacionado. En su petición presentó nueve testigos que refirieron sus méritos, los cuales decían que era de «buena teología, es buen muchacho virtuoso y hombre de bien y de buena fama». Entre ellos había dos comerciantes, don Juan del Allodilio (sic) de 65 años y Juan de Valladolid de 61 años; también convocó a españoles avecindados en la Ciudad de México: José de Solís de 36 años y Jorge Pérez Solís de la misma edad; otro de sus testigos era un regidor del cabildo de la Ciudad de México: don Tomás Justiniano, con quien mantuvo una estrecha relación por unos 10 años ${ }^{49}$.

Dentro del mundo religioso lo recomendaron con grandes elogios el presbítero Pedro Garcés (45 años), el clérigo Diego López de la iglesia de la Ciudad de México (46 años), Pedro Sánchez (46 años) y el más importante de sus testigos el doctor en teología, maestro en artes y catedrático de filosofía en la Universidad, Hernando Ortiz de Hinojosa de 35 años $^{50}$. De las múltiples habilidades que tenía Juan González de Urbina destacaron sobre manera su domino del otomí: «es el más hábil que hay entre los clérigos en la lengua otomí que es una de las más escabrosas y difícil lengua que hay en esta tierra y también sabe la mexicana $»^{51}$; «da muy buena doctrina en muy buena lengua mexica y otomí que es la lengua que se pretende que lo sepan los clérigos de esta Nueva España porque hay pocos que lo sepan como el dicho Juan González» ${ }^{52}$; «es buen religioso y tiene buena lengua otomí y que hace de mucho provecho con los naturales cual el presente es beneficio en el pueblo de Atlacomulco ${ }^{53}$. A la par del tiempo, sus conocimientos en el otomí le fueron de gran valía con los indios otomíes de San Juan.

Ahora bien, la manzana de la discordia entre el recién llegado cura y el orden político-social de Atlacomulco fueron las congregaciones de los pueblos. Por el documento de congregación sabemos que entre el periodo de 1590 a 1608 hubo dos intentos por reducir a los indios. El primero se dio en 1593 por mandato del virrey Luis de Velasco «ordeno y mando juntar y congregar

\footnotetext{
47 AGI, México, 215, núm. 13, f. 2.

48 AGI, México, 214, núm. 11, f. 11.

49 AGI, México, núm. 11, fs. 9-21 y núm. 13, fs. 1-19v.

${ }^{50}$ AGI, México, núm. 11, fs. 9-21 y núm. 13, fs. 1-19v.

51 Testimonio del doctor Fernando Ortiz de Hinojosa, AGI, México, 215, núm. 13, f. 5.

52 Testimonio de Diego López, AGI, México, 215, núm. 13, f. 4.

53 Testimonio de Juan González, AGI, México, 214, núm. 11, f. 11v.
} 
los pueblos de Xocotitlán y Atlacomulco a don Pedro de Villegas y Peralta en quien dicen estar encomendados y que me han dicho que actualmente se está haciendo la congregación... y al juez congregador haga lo dicho» ${ }^{54}$. La disposición señalaba a dos personajes importantes la familia de encomenderos $\mathrm{y}$ al juez congregador, nótese la ausencia del cura, pero ninguno de estos personajes participó en este intento. Juan González de Urbina tomó las riendas de la primera reducción de tal manera que tuvo muchas dificultades:

... me consta que en muchos de los pueblecillos que dejaron tienen sus iglesias hechas y hay casas fundadas en forma y del pueblo de San Juan se fueron los del sujeto de San Francisco Tepeolulco y San Pedro y otros dos sujetos y del pueblo de Santiago Acosilapa que han de traer del pueblo de San Francisco, se fueron los del sujeto de San Felipe y de la congregación de San Miguel Tlamazcaltzingo [Temascalcingo], se fueron los del sujeto de Santiago y con riesgo de estar en sus puestos como de antes y no he sido poderoso atraerlos a congregación y doctrina ni acuden a las confesiones y a oír misa como deben y sin esto están muchos embarrancados a donde jamás acuden a la iglesia ${ }^{55}$.

La presencia del cura se hizo notar, él instrumentó la congregación bajo el argumento doctrinal de que los indios escucharan las misas dominicales, de tal suerte que Juan González de Urbina tuviera su propio modelo de congregación, trayendo indios de cuatro pueblos mayoritariamente mazahuas, para fortalecer al pueblo de San Juan de los Jarros. No obstante, las pretensiones del cura se vieron claramente desprovistas de validez oficial, ya que no estaba el juez congregador ni el encomendero en sus «ajustes»

Cuadro 2. Movilidad entre los pueblos sujetos en 1593. Según la visión DEL CURA JuAn GonzÁlez de URBina

\begin{tabular}{|l|l|}
\hline \multicolumn{1}{|c|}{ PUEBLOS EN REACOMODO } & \multicolumn{1}{c|}{ PUEBLOS RECEPTORES } \\
\hline San Francisco Tepeolulco & San Juan de los Jarros \\
\hline San Pedro & \\
\hline otros dos pueblos & \\
\hline San Francisco (¿Chalchihuipa?) & Santiago Acucilapa \\
\hline San Felipe & \\
\hline Santiago ¿? & San Miguel Temascalcingo \\
\hline
\end{tabular}

Fuente: AMI-SH, doc. 1, f. 8.

\footnotetext{
${ }^{54}$ Archivo General de la Nación, México (AGN), Indios, vol. 5, exp. 457, f. 121.

${ }_{55}$ AMI-SH, doc. 1 , f. 8 .
} 
¿Cuál fue el motivo por la falta de apoyo de estos actores sociales? Indudablemente le presencia de cura fue un parteaguas en la historia local de Atlacomulco y quizá este sea un filón para comenzar a analizar el papel del clero secular en los pueblos de indios, al reorganizar los espacios y fortalecer a San Juan de los Jarros significaría un desplazamiento de funciones y, sobre todo, el control de la caja de comunidad, en un principio la administración de estos fundos dependía del gobernador, el encomendero y del alcalde mayor, cuestión que fue modificándose con los primeros beneficios eclesiásticos asignados, ya que el cura podía tener una llave por razón de los gastos generados en las fiestas patronales. Así es que la tarea de Juan González era desestimar la cabecera:

... que en esta cabecera y pueblo de Atlacomulco se mandaron poner al pie cuatrocientos indios, se les señalaron solares, hicieron sus casas y estaba en forma de pueblo con sus calles y dentro de pocos días se deshizo todo y dejaronlo desierto y no hay en él doscientos indios porque los demás se han ido a sus puestos. Vuestra majestad mande pedir el padrón de los que ahora hay y pedir cuenta de los demás y hacerlos venir y ponerlos en orden para que se puedan administrar y doctrinar ${ }^{56}$

De los 400 indios traídos de los pueblos sujetos huyó la mitad sin dejar rastro alguno, circunstancia que inconformó al cura Juan González de Urbina y, por lo tanto, le solicitó al rey el padrón para obligar a los naturales a regresar al lugar que se les había indicado, pero no hubo respuesta. A todas luces los indios se resistieron, no querían dejar sus sitios inmemoriales, aunado al problema étnico. El cura dio fe de lo complejo del área: «hay en este partido tres lenguas, mexicana, otomie y mazahua, esto es lo que hay en este partido» ${ }^{57}$.

Aún faltan estudios que centren su atención en los problemas étnicos de los pueblos de indios aun cuando el fenómeno entre etnias no fue del todo novedoso, ya que desde la época prehispánica el patrón de asentamientos era de un continuo dispar: para el valle de Toluca había otomíes, nahuas y matlatzincas. En nuestra zona de estudio, los pueblos sujetos de San Juan de los Jarros ${ }^{58}$, San Miguel Temascalcingo ${ }^{59}$ y Santiago Acucilapa ${ }^{60}$ tenían una población distribuida entre otomíes, mazahuas y unos pocos nahuas.

\footnotetext{
${ }^{56}$ Idem.

${ }^{57}$ Ibidem, f. 49v.

58 Idem.

${ }^{59}$ Idem.

${ }^{60}$ Idem.
} 
El esfuerzo del cura por congregar a los pueblos de Atlacomulco no prosperó, había un inminente choque y resistencia por parte de los indios, además de la nula participación de tres actores importantes: el encomendero, el gobernador y el juez congregador ${ }^{61}$. Dicha afrenta, el cura no la olvidó, aliándose con los linajes primigenios del pueblo de San Juan de los Jarros, por ese motivo en la segunda etapa de congregación las cosas cambiaron completamente.

La Congregación de 1604: Juan González de URbina, De Cuidador De ALMAS A LÍDER LOCAL

El cuatro de marzo de 1604 se presentó el juez congregador Andrés de Estrada por mandato del virrey Marqués de Montesclaros, para ejecutar finalmente la congregación de Atlacomulco. En esta ocasión se reunieron el gobernador Francisco de Villegas y el cabildo indígena, los cuales recorrieron y congregaron los pueblos sujetos de Atlacomulco. Por su diversidad étnica contrataron tres intérpretes para hacerles entender a todos los indios cómo debían quedar. En la descripción que hizo el juez congregador contabilizó el número de tributarios de cada pueblo, hizo referencia a su lengua, las tierras del común repartimiento que trabajaban y la distancia que hacían a la cabecera.

El juez de congregación señaló que: «en este pueblo de Atlacomulco declararon por hablar en común la lengua macegual, y el gobernador, alcaldes y gente principal hablar la mexicana $\rangle^{62}$. Los indios de San Juan de los Jarros ocuparon la mayoría de los cargos en el cabildo, había entre ellos principales que hablaban otomí y mazahua (considerada «lengua macegual»); pero sabían hablar náhuatl como lengua franca.

El total de población tributaria en Atlacomulco era de 1,819 y «trescientos y veinte y cuatro de ellos están poblados en la dicha cabecera y los demás repartidos en cuatro sujetos y que todos están en tierra fría y algunos en tierra templada como aparecerá en la visita» Andrés de Estrada consideró cuatro pueblos sujetos importantes para que cada uno hiciera su congregación.

${ }^{61}$ Es probable que la inacción de estos actores políticos se debiese al plan que tenía el cura Urbina, sobre todo para reforzar poblacionalmente a San Juan de los Jarros con respecto a los demás pueblos sujetos, incluyendo a la cabecera. Motivo por el cual, el encomendero, el gobernador y el juez, no permitieron esos reajustes.

${ }^{62}$ AMI-SH, doc. 1, f. 39. 
Cuadro 3. Pueblos receptores de Atlacomulco en 1604

\begin{tabular}{|l|l|}
\hline \multicolumn{1}{|c|}{ PUEBLOS RECEPTORES } & \multicolumn{1}{c|}{ LUGARES CONGREGADOS } \\
\hline San Juan de los Jarros & 7 pueblecillos \\
\hline San Miguel Temascalcingo & 5 pueblecillos \\
\hline San Francisco Chalchihuapan & 4 pueblecillos \\
\hline Francisco Tepeolulco & Santiago Acucilapa \\
\hline
\end{tabular}

Fuente: AMI-SH, doc. 1, fs. 39-44 y 47-50.

Los ajustes y reacomodos territoriales de los pueblos fueron avalados por el juez congregador, pero quien estuvo atrás de ello fue el cura Juan González de Urbina.

San Miguel Temascalcingo fue unos de los pueblos sujetos más importantes de nuestra zona de estudio, de allí procedían los caciques que gobernaron Atlacomulco por varias generaciones. Contaban con 680 tributarios más la gente de sus pueblecillos que se congregaron, sumaban en total 800 tributarios $^{63}$. Era el pueblo con mayor número de habitantes, por ello el cura Juan González de Urbina no podía atenderlos adecuadamente, además de las fricciones con el cacique, por lo cual, pidió al arzobispo otro cura para administrar los sacramentos. Por su parte, los indios se dedicaban a cultivar maíz, frijol y chile en una sementera que medía 20 brazas cuadradas por cada tributario ${ }^{64}$; medida generalizada para todos los pueblos sujetos.

A la par de la producción de sus tierras de comunidad los indios tenían «pocas granjerías, dase bien el maíz y solo para su comer y pasan su año, siembran y cogen y venden muy poco para pagar sus tributos, crían aves de

63 Ibidem, f. 49.

${ }^{64}$ Ibidem, f. 40. En las congregaciones se repartían dos tipos de tierras: en primer lugar, solares para la construcción de sus casas y un pequeño espacio para una huerta familiar; las medidas variaban. Por ejemplo, en Malinalco la superficie estándar era de 20 por 10 brazas (Menegus y Santiago, 2014: 40-41). En Xocotitlán en un principio la media era de 20 brazas cuadradas, pero los indios se inconformaron por ser una medida pequeña, al final la resolución fue darles 30 brazas (ver AGN, Congregaciones, vol. 1, exp. 219, f. 110). En los pueblos de Michoacán la asignación superficial fue de 25 varas cuadradas (Lemoine, 1960:19-32). Para el caso de Atlacomulco y San Juan de los Jarros no se especifica la medida. Estos solares eran repartidos a los indios casados, solteros, solteras, viudos y viudas. El segundo tipo de tierras eran para sembrar y obtener la producción para el tributo (también conocidas como tierras del común repartimiento). 
la tierra y de castilla que le dan bien y le traen a vender» ${ }^{65}$. Como se puede notar la economía indígena se diversificaba en varias actividades.

El cura Juan González de Urbina describe la prosperidad económica de un linaje: «algunos principales que son contados tienen ovejas, vacas y bueyes, crían algún ganado prieto y siembran cantidad de maíz, estos son los que lucen y tienen algún dinero» ${ }^{66}$. Esos principales que refiere el cura, sin duda alguna, son el propio Francisco de Villegas, con sus hijos Juan Ramírez de Tapia, Gabriel Ramírez de Villegas y Agustín Chimal ${ }^{67}$.

El asentamiento de San Francisco distaba de la cabecera aproximadamente 1,5 kilómetros y se ubicaba al sureste donde había «muy buenas ciénagas» ${ }^{68}$. Por sus recursos hidrológicos los indios se dedicaban a la crianza de cerdos, adecuaron su espacio para elaborar abrevaderos y así saciar la sed de sus ganados. También en sus sementeras sembraban todo tipo de legumbres, con especial cuidado del haba. Por la descripción del cura podemos conocer las características territoriales donde se asentaron para vivir: «está asentado en un llano... y está cerca que se oyen las campanas de uno y otro pueblo... es muy buena tierra del temple de la cabecera, hay muchas fuentes de agua que corren por el dicho pueblo y riegan mucha tierra en los llanos y tienen cerca el monte ${ }^{69}$ Por su cercanía a la cabecera el juez congregador propuso mudar cerca de 66 indios para repoblarla; ante la protesta enérgica de estos naturales el juez congregador determinó: «no le saquen los sesenta y seis para poblar en la cabecera y se queden en él $\gg^{70}$

Sobre la movilidad de los indios a sus nuevos espacios hay ciertos rasgos que enuncian medidas laxas que permitían «libertades» a los indios si no les gustaba el sitio o barrio señalado.

Otras de las ventajas que tenía San Francisco, además de tener recursos hidrológicos abundantes, fue su cercanía al cerro de Xocotepetl cuya altitud

${ }^{65}$ AMI-SH, doc. 1, f. 49.

${ }^{66}$ Idem.

${ }^{67}$ En 1598 Francisco de Villegas comenzó con la compra de una estancia para ganado menor y dos caballerías, dos años más tarde adquirió también por compra cuatro estancias para ganado menor, y en 1610 dos caballerías de tierras. Su hijo Juan Ramírez de Tapia, en su testamento, dejó constancia de sus posesiones territoriales. Tenía ocho estancias para ganado menor y seis caballerías de tierras. Gabriel Ramírez poseía cuatro caballerías de tierras y una estancia para ganado menor. Agustín Chimal fue dueño de una veta argentífera, hacienda de minas, partes de minas y un molino de ingenio de moler metales y una hacienda llamada San Antonio de Padua.

${ }^{68}$ AMI-SH, doc. 1, f. 40.

${ }^{69}$ Ibidem, f. $48 \mathrm{v}$.

70 Ibidem, f. 43. 
sobrepasa los 3.800 metros sobre el nivel del mar. Posiblemente los indios se dedicaron a la extracción de madera fina (cedro y fresno) y a la comercialización del carbón y el ocote. Para finalizar, el grupo étnico predominante eran los mazahuas que labraban una sementera de 20 brazas en cuadra.

Hay un asunto que merece toda la atención entre los pueblos de San Francisco Tepeolulco y Santiago Acucilapa. Al parecer tienen la misma raíz histórica desde épocas prehispánicas. Por la descripción que da el documento de congregación, sitúa a Santiago como «pueblo pasajero para la provincia de Michoacán y Guadalajara y otras partes» hoy en día ese lugar lo ocupa Tepeolulco (al oeste de la cabecera), dado que Santiago se encuentra diametral opuesto a la ubicación que el memorial refiere (al este).

En cuanto a su población, Santiago Acucilapa era el pueblo más pequeño (tan sólo 142 tributarios) de toda la corporación de Atlacomulco, en su mayoría eran mazahuas. Al notar la cantidad tan baja de tributarios, el cura Juan González de Urbina le propuso al juez congregador Andrés de Estrada congregarlos al pueblo de san Francisco Tepeolulco que en ese momento contaba con 250 tributarios; en total entre los dos pueblos hicieron $400^{71}$.

Por su ubicación y su carácter de pueblo pasajero, los indios de Acucilapa comercializaban el pulque para la zona minera de Tlalpujahua, además de cárnicos derivados del puerco. Al igual que san Francisco Chalchihuiapan contaba con una ciénaga lo que generaba mayores dividendos para la siembra de hortalizas y legumbres. También es de resaltar la producción del huautli (amaranto); por las crónicas de Diego Durán conocemos que era una semilla que ocupaban para dar forma a las deidades como Huitzilopochtli ${ }^{72}$ y se utilizaba como remedio curativo y preventivo de enfermedades gástricas ${ }^{73}$.

En el documento de congregación hay un constante reclamo y desestima por parte del cura Juan González de Urbina en contra de la cabecera de Atlacomulco. Desde su primer intento fallido en 1593, trató de asentar 400 indios a la cabecera, pero huyeron 200. Para 1604 se contabilizaron en total 324 tributarios, por lo tanto, en un lapso de once años pudieron concretar una repoblación con la llegada de 124 indios a la cabecera. Por los reportes del cura, en 1608 la cabecera contaba con 300 tributarios. En menos de 15 años la población de la cabecera estaba en constante reacomodo, en el documento de congregación no hay una descripción detallada de la organización territorial de la capital de Atlacomulco.

Así se manifestó el cura:

\footnotetext{
71 Ibidem, f. 42.

72 Durán, 1967: 160-161.

73 Hernández, 1959: 389.
} 
Con el juez de esta congregación de Atlacomulco recibí la de vuestra excelentísima y por ella veo la merced que me hace en elegirme por acompañado para que se concluya acudir a su ejecución con el cuidado y diligencia que vuestra excelencia verá porque mi deseo ha sido siempre verla acabada pues de ello ha de redundar tanto servicio a nuestro señor, solo advierto a vuestra excelencia, que queda esta cabecera muy desacomodada y con muy poca gente que por la iglesia y casa no le mudo a otro lugar, así muerto y huido la más partes de ellos y pues lo que su majestad pretende es que los pueblos congregados tengan orden y policía y pasen de cuatrocientos indios y allí esté el ministro me parece que las visitas que son San Juan y San Francisco, se saquen los que faltan y se les den sus solares para que hagan sus casas que respecto de estar tan cerca las dichas visitas, no se les hará muy dificultoso pues con esto gozarán de bien espiritual y de sus tierras que las ternan más a mano, en lo demás se va procediendo conforme a la instrucción que vuestra excelencia me envió y se hace con mucha suavidad y gusto de los naturales y siempre daré aviso de lo que se fuere haciendo guarde nuestro señor a vuestra excelentísima, y en mayor estado aviente con la salud y vida que yo deseo... Juan González de Urbina ${ }^{74}$.

En su retórica hay una llamada de atención muy fuerte: «sólo advierto» (negritas añadidas); y en su queja el cura manifestaba dos problemas: el lugar y la cantidad de personas. En cuanto a su configuración territorial, la cabecera de Atlacomulco no tiene descripciones tan detalladas como la de sus pueblos. Al parecer, contaba «con cuatro pueblecillos sujetos y por ser mala tierra y carecer de agua y leña no está mejor poblado» ${ }^{75}$; nótese la queja continua del cura. Ahora bien, ¿por qué tanta animadversión contra el asentamiento de la cabecera? En el contexto general de Atlacomulco durante la segunda mitad del siglo XVI y las primeras dos décadas del siglo XVII hay una continua lucha por el poder económico. Desde su llegada, el encomendero don Francisco de Villegas rápidamente se convirtió en terrateniente, realizó una alianza con los mazahuas de Temascalcingo, pacto que consistió en la permanencia política de estos indios en el poder, y tuvo a su cargo la administración conjunta de la caja de comunidad creada en 1550; lo cual propició un status quo que duró varios decenios, hasta la llegada del cura Juan González de Urbina.

Cabe destacar que, en la congregación de Jarros, el cura participó de manera activa juntamente con el juez congregador $y$, en cierto sentido, obligado, el gobernador Francisco de Villegas. Cada vez que el gobernador Villegas no apresuraba la reorganización espacial y la edificación de las casas a los indios de San Juan, el cura González de Urbina arremetía en contra de él,

\footnotetext{
${ }^{74}$ AMI-SH, doc. 1, f. 47-47v.

${ }^{75}$ Idem.
} 
denunciándolo al juez congregador, mismo que amenazó al gobernador en propiciarle 100 azotes y ser removido de su cargo ${ }^{76}$.

En general, el cura Juan González de Urbina tuvo un papel determinante en la congregación, de hecho, en su descripción aludió a San Juan de los Jarros como «haber sido república de alcaldes y demás oficiales» ${ }^{77}$ ¿Qué de relevante tenía cada una de estas palabras? El concepto república, bajo el contexto de los pueblos de indios, se entendía como aquella entidad política conformada por un aparato jerárquico en donde se circunscribían vínculos de poder y parte de su integración estaba encabezada por un gobernador y su respectivo cabildo (alcaldes, regidores, alguaciles y escribanos). A la luz de la evidencia documental, desde el virrey Antonio de Mendoza se tenía el objetivo de crear un sistema de organización en dos aspectos básicos: el administrativo y el espiritual. En relación con estas pretensiones se determinó lo siguiente: «Cada pueblo que pasaren de ochenta casas tuviera un gobernador, dos alcaldes y dos regidores ${ }^{78}$.

El principio del orden y policía estaba en ejecución, con el nombramiento de estos oficiales se constituyó la república de indios, cuyos miembros eran conocidos como «oficiales de república»; por ello las palabras del cura tenían un significado especial. Sin duda alguna, se alude a un pasado importante, donde algunos principales posiblemente gobernaron en tiempos remotos y aún la élite tenochca gozaba de cierta relevancia en la época colonial.

Cuando el cura Juan González llegó a Atlacomulco en 1575 encontró una serie de irregularidades, las finanzas del pueblo estaban sujetas bajo la determinación del encomendero y los caciques, por ello desde un principio González de Urbina solicitó la ayuda del rey para sus gastos y los de su parroquia (obligación que le correspondía al encomendero). A raíz de estas desavenencias con los actores implícitos en el poder, el cura estudió la conformación de Atlacomulco, analizó cada uno de los pueblos sujetos y encontró en San Juan un bastión importante, una organización de cierta manera autónoma de la cabecera constituido por estancias y barrios, y cada una de esas estancias estaban administradas por un principal de linaje, por ese motivo, el cura pretendió desplazar a la cabecera de Atlacomulco, así le restaría poder a los intereses generados.

Por el testimonio del cura conocemos cómo fue el proceso de congregación de San Juan. El domingo 11 de mayo de 1603 después de la misa dominical ${ }^{79}$

76 Ibidem, f. 73-73v.

77 Ibidem, f. 2v.

${ }_{78}$ Recopilación de las leyes..., 1681, libro VI, título III, ley XIX.

79 En Malinalco casualmente también se ejecutó el domingo 11 de mayo de 1600. Al igual que en Jarros, hicieron acto de presencia el juez congregador, los frailes y el cabildo indio. 
se llamó a los indios a escuchar las palabras de Jorge de Baeza y Carvajal (juez congregador) y del cura Juan González de Urbina; en esta ocasión no utilizaron intérpretes ya que el bachiller era versado en el otomí y en el mazahua. Las palabras referidas estaban encaminadas a señalar a los indios sus nuevos espacios, los beneficios que conllevaba todo el proceso y la protección de sus tierras inmemoriales ${ }^{80}$.

Es de notar que el gobernador Francisco de Villegas no acudió a esta primera cita; inclusive Jorge de Baeza al terminar de explicar la congregación a los indios hizo referencia que su siguiente pueblo a visitar era San Miguel Temascalcingo, cuna del propio gobernador, no obstante, el cura le comentó que estaban renuentes los indios de San Miguel. Al escuchar el juez el comentario de Juan González determinó que el próximo domingo visitaría al pueblo de Temascalcingo:

... y que en dicho pueblo estén sus mujeres e hijos y el auto que tuviesen y estuviese cada uno de ellos en su casa viviendo en apercibimiento que no lo cumpliendo ( sic) el dicho juez los castigará y echarles las casas en el suelo y para mayor brevedad quemárselas mandó parecer ante sí a don Francisco de Villegas gobernador en el cual mediante, el dicho intérprete preguntó si los dichos indios habían venido al dicho pueblo como se les había mandado y el dicho gobernador dijo que si habían venido los cuales con sus mujeres e hijos puso ante el dicho juez y ante el dicho beneficiado y por lengua del dicho intérprete se les apercibió y mandó que son naturales de este dicho pueblo y tienen sus casas en él, no se ahuyenten ni se vayan a vivir a otra parte ni al dicho sitio de donde fueron traídos so pena de ser ahorcados (sic) en la horca del dicho pueblo, y habiéndoles hecho otras amenazas y apercibimientos por lengua del dicho intérprete respondieron que están prestos de lo cumplir y de no salir del dicho pueblo para vivir en otra parte ${ }^{81}$.

Al parecer la ausencia del gobernador molestó al juez congregador, por ello le exigió su presencia en Temascalcingo, inclusive le advirtió que no permitiría ninguna resistencia por parte de los indios para mudarse a sus nuevos espacios, y si alguno persistía en desacatar la orden se tomarían medidas radicales como la quema y destrucción de sus jacales ${ }^{82}$. Pero antes de acudir

Se leyó la orden «tanto en lengua castellana y en la mexicana» (Menegus y Santiago, 2014: 21-33. Santiago, 2012: 25-26).

${ }^{80}$ AMI-SH, doc. 1, f. $12 \mathrm{v}$.

${ }^{81}$ Ibidem, fs. 13-13v.

82 Era la medida más radical de los jueces de congregación para que los indios no regresaran a sus sitios viejos y se ejecutó en la mayoría de los pueblos del valle de Toluca. Tal fue el caso de Xalatlaco: «sabed que los naturales del dicho pueblo de Xalatlaco me hicieron relación les queréis derribar y desbaratar algunas casas de muy buen oficio diciendo están algo apartadas y derramadas» (AGN, Congregaciones, vol. 1, exp. 107, f. 66). Una situación 
el juez congregador mandó a su intérprete Baltasar Mejía para hacer una averiguación sobre la colaboración del gobernador en la congregación de su pueblo; sin retardo alguno, Baltasar entrevistó a cada uno de los naturales y todos declararon a favor de don Francisco de Villegas, es decir, dijeron que ya les había persuadido para que se congregasen. No cabe duda, la relación entre el cura y el gobernador era de continuo malestar.

Ya con la amonestación, don Francisco de Villegas acompañó al encomendero Alonso de Basan ${ }^{83}$, al juez congregador y al cura para comenzar formalmente los trabajos de reducción: «y llegamos este dicho día serían como las dos de la tarde poco más o menos al dicho pueblo san Juan Cuiyatepec yo Baltasar de Contreras [el juez congregador] $\rangle^{84}$

El recorrido comenzó por el centro de San Juan y de allí partió a la periferia. El juez congregador y su intérprete observaron que: «el dicho pueblo y barrios es muy bueno y está en muy buen asiento en traza y policía que parece ciudad... y así mismo le señaló la plaza que tenían a las espaldas de la dicha iglesia en la delantera y les señaló para casas de comunidad y cárcel y cabildo que no las tenían hechas ${ }^{85} \gg$. Hay varias cuestiones que discutir de estas afirmaciones.

En primer lugar, cobran relevancia los conceptos ya señalados; aquí se ve claramente la seña particular de llamarle «pueblo» a San Juan, para distinguirlo de sus propios pueblecillos y barrios. Aunado el concepto, también se pueden vislumbrar ciertos elementos que enuncian la importancia de Jarros con respecto a la cabecera de Atlacomulco. Según las reformas que estableció el rey Felipe II en 1573, referente a las ordenanzas de población, señaló que cada centro urbano debía tener una plaza central y que de ella se desprendieran cuatro calles principales, además se requería tener mucho cuidado con el templo religioso de tal manera que su establecimiento se respetara, guardando toda proporción, entre las plazas de la iglesia parroquial y las capillas ${ }^{86}$. Tam-

similar ocurrió al pueblo de Capulhuac: «se me hizo relación les queréis derribar algunas casas de su pueblo por decir estar fuera de policía y derramadas» (AGN, Congregaciones, vol. 1, exp. 95, f. 62v.) Para Malinalco hay varias menciones de derrumbe de casas «sus caciques dispusieron mandase derribar y derribaron todas las casas de los naturales y las quemase» (Menegus y Santiago, 2014: 52-53).

${ }^{83}$ A la salida de Pedro de Villegas, la Corona se ocupó de administrar la encomienda en 1595, sin embargo, fue reasignada en 1604.

${ }^{84}$ AMI-SH, doc. 1, f. 15.

${ }^{85}$ Ibidem, f. 16.

${ }^{86}$ El orden que se ha de tener en descubrir y poblar..., 1973: 86-92. 
bién dentro del casco urbano se instaba a dejar «sitio y solar para la casa real casa de consejo y cabildo y aduana junto al mismo templo ${ }^{87} \gg$.

Por las características que señala la ordenanza, prácticamente el centro de San Juan de los Jarros era considerado como un centro urbano, cumplía con todo lo indicado, tenía su plaza principal en frente del templo, cárcel y la casa de comunidad, donde se hacían las labores gubernativas.

En comparación con los demás pueblos sujetos, su número de tributarios (398) superaba a la cabecera de Atlacomulco, no así Temascalcingo. En cuanto a su conformación étnica se encontraban otomíes, mazahuas y nahuas. Uno de los barrios más importantes de San Juan era San Bartolomé; un pequeño lugar que albergó un sector importante de mexicas y fueron los únicos que conservaron su apellido original; en 1655 defendieron sus tierras de la invasión de doña Margarita y su esposo Francisco Rodríguez quienes pretendían extender sus dominios ${ }^{88}$. Este barrio cultivaba magueyes y vendía el pulque en la zona minera de Tlalpujahua ${ }^{89}$. De los otros barrios no hay una descripción detallada, al parecer tenían cerdos y aprovechaban los beneficios de vivir en ciénaga. Tenían tierras para cultivar maíz y algunas legumbres, su cantidad no variaba del resto de los pueblos sujetos, 20 brazas cuadradas.

Por testimonio del cura podemos saber más características:

El otro puesto se dice San Juan está puesto en una loma alta una legua de la cabecera, de manera que queda en medio y las dos visitas una a un lado y otra, otro juntáronse aquí siete pueblecitos y quedaron trescientos noventa indios tributarios, por estar en loma el pueblo no entra agua en él y van por ella dos o tres tiros de arcabuz de allí es tierra fría y airosa ${ }^{90}$.

Efectivamente, hoy en día el establecimiento de Jarros se encuentra en las laderas de una pronunciada sierra, que funge como frontera natural con el pueblo de Temascalcingo. Las ubicaciones de las tierras del común repartimiento se encontraban al norte, allí estaba la ciénaga para abastecerse del líquido vital. Una vez terminado el proceso de congregación, como bien lo refiere el cura Juan González de Urbina, San Juan quedó en medio de san Miguel Temascalcingo y la cabecera de Atlacomulco.

\footnotetext{
87 Ibidem: 88.

${ }^{88}$ AGN, Indios, vol. 18, exp. 6, f. 2v.

${ }^{89}$ AGN, Indios, vol. 10, exp. 254, f. 146v.

90 AMI-SH, doc. 1, f. 48v.
} 
Mapa 3. Congregación de san Juan de los Jarros

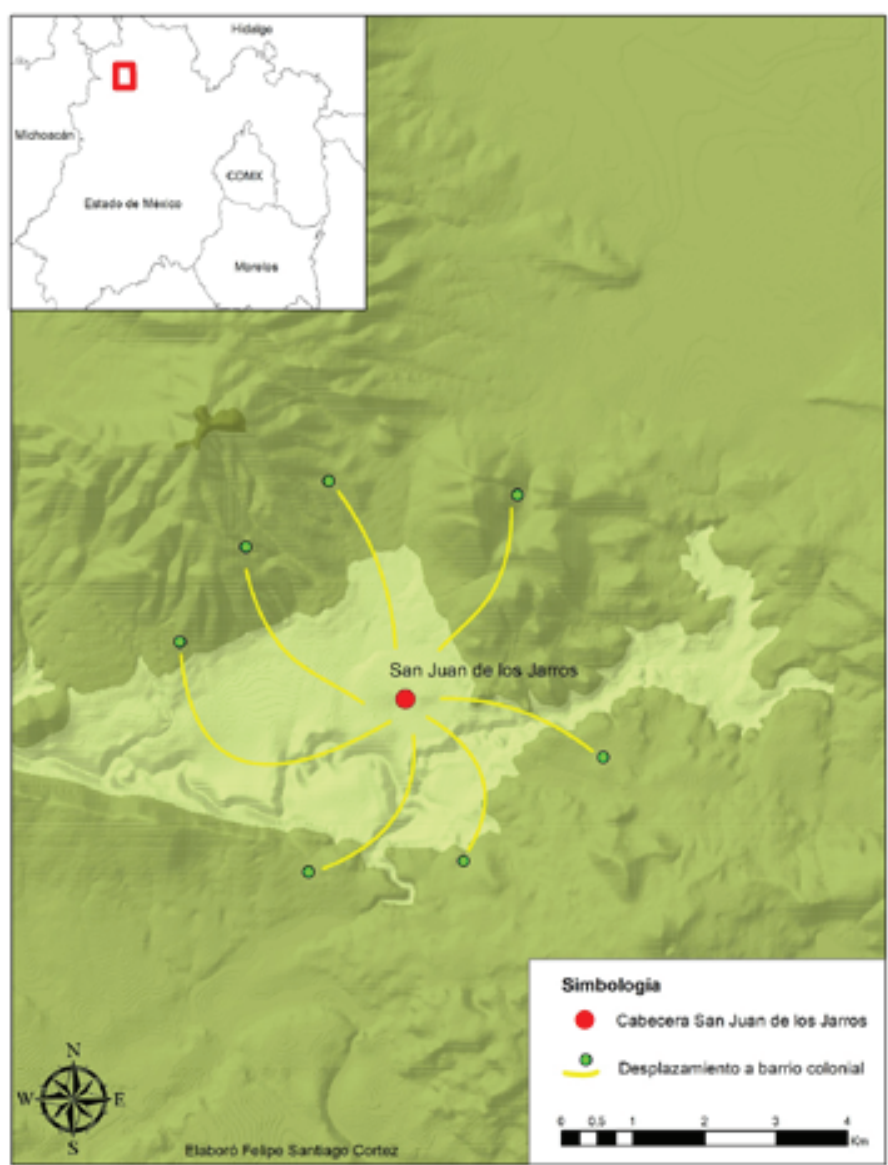

Fuente: Reconstrucción hipotética a partir del AMI-SH, doc. 1, fs. 29-43.

Uno de los procesos más demandantes durante la congregación fue la edificación de las casas. En realidad, todavía existía resistencia por parte de los indios en hacerlas y habitarlas, recordemos que en Atlacomulco se presentó el juez congregador por vez primera el 11 de mayo de 1603 para informar a todos los indios las ventajas de reducirse; no obstante, para el mes de enero de 1606, los indios de San Juan no se mudaban y estaban en el proceso de edificar sus viviendas. Sin duda alguna, uno de los factores determinantes para designar los materiales a ocupar fue el clima, regularmente durante los meses invernales la temperatura desciende de una manera muy notable, 
por ello las casas debían tener ciertas particularidades para protegerse del frío. Por las instrucciones que dio el juez congregador los materiales que ocupaban eran: la paja, los moldes para hacer el adobe y algunas vigas para el techo ${ }^{91}$. El trabajo era arduo para un sólo indio, por ello se instaba a los tequitlatos a supervisar los trabajos y a organizar de 8 a 12 cuadrillas (configuradas por 20 indios) para edificar ${ }^{92}$.

El trabajo no terminaba ahí, un agrimensor avalado por el juez congregador medía los solares a repartir; cada indio (soltero, soltera, viudo, viuda y casados) recibía una superficie de 25 varas de largo por 20 de ancho ${ }^{93}$. Por cada solar repartido «señalándole luego con alguna zanja o mojonera se ha de edificar de balde un aposento alto» ${ }^{94}$, es decir una barda perimetral que hacía la distinción superficial entre cada solar repartido.

Hasta aquí prácticamente, el juez congregador y sus ayudantes tuvieron una participación, sin embargo, en la distribución de las habitaciones el cura Juan González de Urbina ponía mucha atención. En primer lugar, debía haber un espacio que «distinga la vivienda del servicio en que hubiere de ver inmundicias» además de señalar «el dormitorio de los hijos del de las hijas... esto para que en todo caso lo cumplan y se introduzca algo de policía cristiana entre ellos ${ }^{95}$. La observación del cura en las viviendas fue muy puntual, la composición era «una sala y a cada lado un aposento y frontero de este cuarto están otros dos aposentos que el uno sirve de cocina y es casa de barros convajerada [bajareque] de terrado ${ }^{96}$. Además de ello, todos los indios se mudaban «con sus ropas y bienes y barbacoa», la palabra barbacoa proviene del taíno y fue introducida al español, significa tejidos de ramas; en la Nueva España era el petate y se aplicaba para definir el sitio donde iba la cama. ${ }^{97}$

91 Para el caso de Malinalco, las casas eran más sencillas, estaban hechas de carrizo que fungía como pared, y el techo era paga. (Menegus y Santiago, 2014: 87-88).

${ }_{92}$ AMI-SH, doc. 1 , f. 26.

93 Ibidem, f. 24v. Desafortunadamente no podemos comparar las dimensiones que estaban dadas en varas con otros pueblos (Malinalco, 20 por 10 brazas; Xocotitlán, 20 brazas encuadra) cuyas superficies eran en brazas cuadradas. El problema de ello es que había varas castellanas y varas matalcinga, el documento no especifica el tipo de vara con la cual se midió.

${ }^{94}$ AMI-SH, doc. 1, f. 24v.

95 Ibidem, f. $25 \mathrm{v}$.

96 Ibidem, f. 93v.

${ }^{97}$ Romero, 1862: 108. 
Esquema 1. Distribución de los ESPACIOS EN UNA CASA

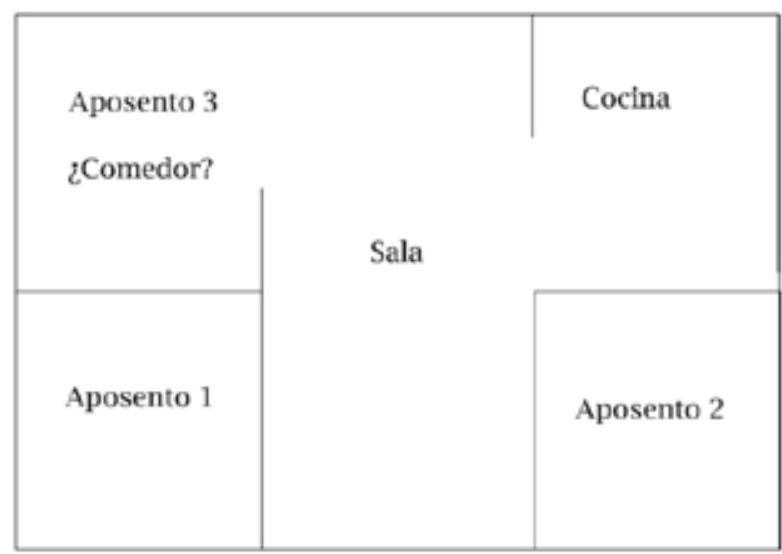

Fuente: Reconstrucción hipotética a partir del AMI-SH, doc. 1, f. 93.

Cada principal tenía la obligación de velar por los trabajos que se hacían en la congregación; desde los tiempos de Luis de Velasco (el mozo) había algunas casas que todavía quedaban en pie «faltan por hacer y comenzar mucha cantidad de casas para todos los indios que en él viven y están reducidos desde el tiempo del virrey Luis de Velasco ${ }^{98}{ }^{9}$, por ello en la descripción del documento se mencionan que son reedificadas a partir de los cimientos que tenían (según el documento todas las viviendas tenían una base de piedra) desde 1593.

Respecto a don Francisco de Villegas, nuevamente tuvo problemas con el cura. A Juan González de Urbina le urgía terminar la congregación de San Juan, al notar que los años pasaban y que los indios no procuraban construir o reparar las casas, tuvo que acusar al gobernador ante el juez congregador. El 17 de junio de 1608 se presentó una comitiva encabezada por el juez, el cura y todo el cabildo indígena; se encontraron con «las casas despobladas que son indios de los dichos pueblos viejos los cuales han sido de ordinarios rebeldes y no obedientes a no querer vivir en este pueblo99 $\gg$. Averiguando el cura más sobre este asuntó, les preguntó a los indios cuales eran los motivos para no habitar sus nuevos espacios y expresaron: «sino que con achaque de que van a sembrar sus tierras y que les caen cerca, se van a los dichos puestos como se han ido y se han quedado al presente... y que vivido en ellas

\footnotetext{
${ }^{98}$ AMI-SH, doc. 1, f. 56v.

99 Ibidem, f. $72 \mathrm{v}$.
} 
estando enfermos y yéndose a curar a casa de sus parientes por no estar solos y haber acudido a sus sementeras a los puestos viejos» ${ }^{100}$.

Ante tales argumentos poco fiables, Juan Ramírez Escobar «reprendió al dicho gobernador por el descuido que ha tenido en todo lo susodicho y le mandó so pena de que será castigado y removido del oficio que luego vaya personalmente y a todos puestos viejos que tienen declarados» ${ }^{101}$. Con tal amenaza vertida en sus espaldas, don Francisco de Villegas fue a cada puesto y de manera enérgica les habló en mazahua «y los reprendió y amenazó que so pena de cien azotes que se les serán dados por las calles» ${ }^{102}$. No bastaba con los azotes, había una humillación pública para todo aquel que resistiera la reducción. Con estas medidas radicales el gobernador salvó su puesto y así fue como se concretó la congregación de San Juan de los Jarros.

\section{CONCLUSIONES}

Este artículo intenta esclarecer ciertas ideas y formular algunas hipótesis en torno al proceso de las congregaciones de los pueblos de indios. Para ello, he considerado pertinente partir de un eje temático ausente en la historiografía, con el caso de un cura cuya participación es notable, no solo en la organización de un pueblo (lo cual en sí ya sorprende e invita al estudio), sino también en la vida económica, social y política de una corporación. No está por demás insistir en que el estudio de las congregaciones reviste una singular importancia en la historiografía colonial, más aún si se realiza a partir de fuentes inéditas, como los documentos de congregación, en los que aparecen personajes ya conocidos: encomenderos, caciques, el juez congregador $\mathrm{y}$, sumémosle, los curas, vistos ahora como líderes sociales cuya tarea sobrepasó el carácter espiritual.

Ríos de tinta han corrido sobre los problemas en las esferas eclesiásticas que la mayoría de los pueblos de indios tuvieron en su proceso de secularización, sin embargo, falta analizar con casos particulares el desempeño de los curas dentro de las corporaciones; sobre una revisión historiográfica como un mosaico general y cimiento, quizá este trabajo sea una contribución para ver la tarea del clero secular en todas sus dimensiones. Por lo aquí expuesto tengo la impresión de que, durante su gestión, Juan González de Urbina como líder local procuró por los linajes tradicionales que estaban de cierto modo

\footnotetext{
100 Ibidem, fs. 73-73v.

101 Ibidem, f. 72.

102 Ibidem, f. $73 \mathrm{v}$.
} 
relegados en un pequeño pueblo, San Juan de los Jarros, que por varias décadas no figuró en la escena política de Atlacomulco, sin embargo, su alianza con Jarros llevaba implícito el interés de controlar y administrar la economía de toda la corporación. Ya con la presión del juez congregador, el gobernador y el encomendero se dieron prisa para llevar a cabo el orden y la distribución de las tierras, pero, en el momento en que descuidaban la reducción (sobre todo el gobernador), el cura salía para acusarlo y con ello Francisco de Villegas tuvo amenazas de ser azotado y destituido de su cargo. Cabe recordar que el juez congregador prácticamente se apoyó en el testimonio del cura, y tanto su liderazgo como su conocimiento tuvieron un gran peso en las decisiones sobre el proceso de congregación.

Aún quedan asignaturas pendientes por analizar, creo que las congregaciones pueden ser un filón para incentivar las investigaciones sobre el quehacer del clero secular dentro de los pueblos de indios. Faltan trabajos que nos enuncien las riquezas patrimoniales de los curas y que estudien cómo, quizás, algunos de ellos, al igual que Juan González, se convirtieron durante el siglo XVII en grandes terratenientes y, tal vez, también en controladores del comercio local y regional.

\section{BiBLIOGRAFÍA}

Aguirre Salvador, Rodolfo, "El clero de la Nueva España y las congregaciones de indios: de la evangelización inicial al III Concilio Provincial mexicano de 1585", Revista Complutense de Historia de América, 39 (Madrid, 2013): 129-152.

Aguirre Salvador, Rodolfo, "El tercer concilio mexicano frente al sustento del clero parroquial", Estudios de Historia Novohispana, 51 (Ciudad de México, 2014): 9-44.

Arrioja Díaz Virruell, Luis Alberto, "Las congregaciones de indios y las corrientes de agua en la alcaldía mayor de Nexapa, 1600-1604", Revista fuentes humanísticas, 37 (Ciudad de México, 2008): 75-90.

Chevalier, François, La formación de los latifundios en México. Tierra y sociedad en el siglo XVI y XVII, Ciudad de México, Fondo de Cultura Económica, 1976.

Cline, Howard F., "Civil Congregations of the Indians in New Spain, 1598-1606", The Hispanic American Historical Review, XXIX/3 (Durham [EUA], 1949): 349-369.

Dehouve, Daniele, Cuando los banqueros eran santos. Historia económica y social de la provincia de Tlapa, Guerrero, Ciudad de México, Universidad Autónoma de Guerrero / Centro Francés de Estudios Mexicanos y Centroamericanos, 2001. 
Descripción del Arzobispado de México hecha en 1570, Ciudad de México, José Joaquín Terrazas e hijas imps., 1897.

Durán, Diego, Historia de los indios de la Nueva España, Tomo II, Ciudad de México, Porrúa, 1967.

El Libro de las tasaciones de pueblos de la Nueva España siglo XVI, Ciudad de México, Archivo General de la Nación, 1952.

El orden que se ha de tener en descubrir y poblar. Transcripción de las ordenanzas de descubrimiento, nueva población y pacificación de las indias dadas por Felipe II, el 13 de julio de 1573, en el bosque de Segovia, según el original que se conserva en el Archivo General de Indias, Madrid, Ministro de la Vivienda, Servicio Central de Publicaciones, 1973: 86-92.

Espejo, Juan, Relaciones de méritos y servicios de funcionarios de Chile. Siglos XVIII y XIX, Santiago de Chile, Casa Zamorano y Caperán, 1926.

Farris, Nancy, Maya society. Under colonial rule. The Colletive Enterprise of Survival, Oxford, Princeton University Press, 1992.

García Castro, René, Indios, territorio y poder en la provincia Matlatzinca. La negociación del espacio político de los pueblos otomianos, siglos XV-XVII, Ciudad de México, El Colegio Mexiquense / Consejo Nacional para la Cultura y Las Artes/ Centro de Investigaciones y Estudios Superiores en Antropología Social / Instituto Nacional de Antropología e Historia, 1999.

García Martínez, Bernardo, Los pueblos de la sierra: el poder y el espacio entre los indios del norte de Puebla hasta 1700, Ciudad de México, El Colegio de México, 1987.

Gerhard, Peter, “Congregaciones de indios en la Nueva España antes de 1570”, Historia Mexicana, XXVI/103 (Ciudad de México, 1977): 347-395.

Gerhard, Peter, Geografía histórica de la Nueva España 1519-1821, Ciudad de México, UNAM, 2000.

González Reyes, Gerardo, Señorios, pueblos y comunidades. La organización politico territorial en torno del Chicnahuitecatl, siglos $X V$-XVIII, Ciudad de México, Universidad Autónoma del Estado de México, 2013.

Hernández, Francisco, "Historia de las plantas de la Nueva España", Historia natural de Nueva España, Ciudad de México, Universidad Nacional Autónoma de México, 1959, tomo II.

Jiménez Abollado, Francisco Luis, "Valor etnográfico de las congregaciones civiles de pueblos de indios: la congregación de San Francisco Temango, 1598-1605", Revista Española de Antropología Americana, 39/2 (Madrid, 2009): 41-58.

Lemoine, Ernesto, "Mandamientos del virrey, para la congregación de pueblos de indios en la alcaldía mayor de Valladolid 1601-1603", Boletín del Archivo General de la Nación, I/1 (Ciudad de México, 1960): 11-55. 
Martínez, Hildeberto, Codiciaban la tierra. El despojo en los señoríos de Tecamachalco y Quecholac (Puebla, 1520-1650), Ciudad de México, Centro de Investigaciones y Estudios Superiores en Antropología Social, 1994.

Menegus Bornemann, Margarita y Santiago Cortez, Felipe, La congregación de Malinalco de 1600, Ciudad de México, Biblioteca Nacional y Hemeroteca Nacional / Instituto de Investigaciones sobre la Universidad y la Educación/ Universidad Nacional Autónoma de México, 2014.

Menegus Bornemann, Margarita y Santiago Cortez, Felipe, La congregación de San Juan de los Jarros de 1604, Ciudad de México, Biblioteca Nacional y Hemeroteca Nacional / Instituto de Investigaciones sobre la Universidad y la Educación/ Universidad Nacional Autónoma de México, 2020.

Molina, Fray Alonso de, Vocabulario en lengua castellana y mexicana, Madrid, Cultura Hispánica, 1944.

Paso y Troncoso, Francisco de, "Suma de visitas de los pueblos", Papeles de la Nueva España, Ciudad de México, publicados en orden y con fondos del gobierno mexicano, 1905: 1-105

Pérez Zevallos, Juan Manuel, "Movimientos de población indígena en Nueva España. Siglo XVI", Boletín de Antropología Americana, 30 (Ciudad de México, 1994): 39-60.

Quezada, Noemí, "Congregaciones de indios en el valle de Toluca y zonas aledañas", Manuel Miño (coord.), Mundo rural, ciudades y población del Estado de México, Toluca, El Colegio Mexiquense / Instituto Mexiquense de Cultura, 1990: 71-90

Recopilación de las leyes de indias de 1681, Madrid, Mandadas imprimir y publicar por la Majestad Católica del rey Don Carlos II, Impreso por Ivlian de Paredes, 1681, libro I, título XIII, ley X.

Recopilación de las leyes de indias de 1681, Madrid, Mandadas imprimir y publicar por la Majestad Católica del rey Don Carlos II, Impreso por Ivlian de Paredes, 1681, libro VI, título III, ley XIX.

Romero, José Guadalupe, Noticias para formar la historia y la estadística del obispado de Michoacán: presentadas a la Sociedad Mexicana de Geografía y Estadística en 1860, Ciudad de México, 1994, V. García Torres, 1862.

Santiago Cortez, Felipe, Territorio y gobierno indio en Malinalco, tesis de maestría, Ciudad de México, Universidad Nacional Autónoma de México, 2012.

Solórzano y Pereira, Juan, Política indiana, Madrid, Iberoamericana, 1930, libro 4, cap. 23, núm. 5.

Taylor, William, Ministros de lo sagrado. Sacerdotes y feligreses en el México del siglo XVIII, Ciudad de México, El Colegio de México / Secretaría de Gobernación, Subsecretaría de asuntos religiosos / El Colegio de Michoacán, 1999, vol. II. 
Torre Villar, Ernesto de la, "Las congregaciones de indios en el siglo XVI. Relación de la congregación del pueblo de Tianguistenco, provincia de Meztitlán", Boletín del Archivo General de la Nación, XXIII/2 (Ciudad de México, 1952): 145-213.

Torre Villar, Ernesto de la, Las congregaciones de los pueblos de indios. Fase terminal: aprobaciones y rectificaciones, Ciudad de México, Universidad Nacional Autónoma de México, 1995.

Fecha de recepción: 9 de agosto de 2019.

Fecha de aceptación: 4 de febrero de 2020.

\section{The participation of secular clergy in Indian village congregations: the case of Atlacomulco and San Juan de los Jarros 1592-1604}

This article aims to analyse the secular clergy's participation in Indian village congregations. My contribution to the debate on congregations is to study priests as complex social actors whose role is not limited to their religious activities, but who also act as true negotiators, intermediaries and political agents in the villages. To explore this, I analyse the case of Juan González de Urbina, a priest in Atlacomulco and key figure behind the unpublished document of the Atlacomulco congregation.

KEY WORDS: priests; congregation; colonial town; ecclesiastical benefits. 
